\title{
Totally in
}

\footnotetext{
From the Division of Cardiovascular Surgery, Children's National Heart Institute, Children's National Health System, The George Washington University School of Medicine, Washington, DC Disclosures: Authors have nothing to disclose with regard to commercial support.

Received for publication April 5, 2018; accepted for publication April 9, 2018; available ahead of print May 17, 2016.

Address for reprints: Can Yerebakan, MD, , Children's National Heart Institute Children's National Health System, The George Washington University School of Medicine and Health Sciences, 111 Michigan Ave, NW, Washington, DC 20010 (E-mail: cyerebakan@ childrensnational.org).

J Thorac Cardiovasc Surg 2018;156:741-2

$0022-5223 / \$ 36.00$

Copyright (C) 2018 by The American Association for Thoracic Surgery

https://doi.org/10.1016/j.jtcvs.2018.04.027
}

Mechanical circulatory support for the pediatric population offers short- and long-term circulatory assistance for intractable cardiac failure with continuous improvement in the outcomes. ${ }^{1}$ One of the most frequently used devices is the Berlin Heart Excor assist system, which offers adequate pump sizes and support options for almost the entire pediatric population. ${ }^{2}$ Mechanical circulatory assistance in single-ventricle patients has inferior outcomes due to technical challenges ${ }^{3,4}$ posed by the single ventricle as well as the cavopulmonary connections. Most of these patients except for the older adolescents are not suitable for a total artificial heart. However, in rare circumstances, the Berlin Heart assist device has been safely used as a total artificial heart as a bridge to transplantation even though it was not designed and approved for this indication. 5

In this issue of the Journal, Kato and Gandhi ${ }^{6}$ report the implantation of the Berlin Heart assist device as a total artificial heart in 2 pediatric cases, a newborn patient after a Norwood/Sano palliation and a 14-week-old patient with noncompaction cardiomyopathy. Both patients were successfully bridged to cardiac transplantation. The first patient unfortunately died due to primary graft failure and renal dysfunction after cardiac transplantation. The reason for the use of the Berlin Heart assist device as a total artificial heart in both cases seemed to be the limited intrathoracic space. Technical details of the operation are demonstrated with illustrations by the authors. Particular emphasis is made on the generous reconstruction of the atrial chambers to prevent inflow problems.

Not only being a challenging procedure but also with a potentially complex management in the intensive care unit, this type of support requires a meticulous surgical technique, thorough understanding of the physiological parameters during support, and a dedicated team for a successful outcome. The authors and their entire team have to be congratulated for their outcome of mechanical circulatory assistance in both cases. feasible.

\section{References}

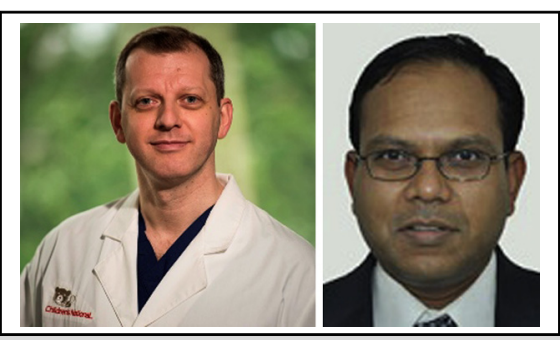

Can Yerebakan, MD, and Pranava Sinha, MD

\section{Central Message}

The use of Berlin Heart Excor as a total artificial heart is feasible in select cases as a bridge to cardiac transplantation.

See Article page 743.

However, cardiectomy with use of the Berlin Heart Excor as a total artificial heart can pose a few unique challenges. First, the postoperative balance of the circulation may indeed be complicated, most likely due to the lacking compliance of the heart chambers even when in the present report the authors mention no challenges with regard to this issue., Their implantation technique by creating large atrial filling chambers may have played a role to overcome such a problem. Second, a complete cardiectomy and the consequent shrinkage of the pericardial space in the interim may complicate the donor allograft implantation. Careful consideration must be given to conventional type of biventricular assistance, and the implantation of the Berlin Heart as a total artificial heart should only be performed in select cases if the standard approach is not

In summary, the exclusive use of the Berlin Heart as a total artificial heart in select cases due to unavoidable technical challenges may offer a reasonable outcome. The literature offers examples of this approach with differing results. ${ }^{7}$ Obviously the limited experience should not lead to the liberalization of this type implantation as a standard alternative means. We thank the authors for sharing their invaluable experience.

1. Stiller B, Hetzer R, Weng Y, Hummel M, Hennig E, Nagdyman N, et al. Heart transplantation in children after mechanical circulatory support with pulsatile pneumatic assist device. J Heart Lung Transplant. 2003;22:1201-8. 
2. Morales DLS, Zafar F, Almond CS, Canter C, Fynn-Thompson F, Conway J, et al. Berlin Heart EXCOR use in patients with congenital heart disease. J Heart Lung Transplant. 2017;36:1209-16.

3. Weinstein S, Bello R, Pizarro C, Fynn-Thompson F, Kirklin J, Guleserian K, et al. The use of the Berlin Heart EXCOR in patients with functional single ventricle. $J$ Thorac Cardiovasc Surg. 2014;147:697-704.

4. Lorts A, Eghtesady P, Mehegan M, Adachi I, Villa C, Davies R, et al. Outcomes of children supported with devices labeled as "temporary" or short term: a report from the Pediatric Interagency Registry for Mechanical Circulatory Support. J Heart Lung Transplant. 2018;37:54-60.
5. Valeske K, Yerebakan C, Mueller M, Akintuerk H. Urgent implantation of the Berlin Heart Excor biventricular assist device as a total artificial heart in a patient with single ventricle circulation. J Thorac Cardiovasc Surg. 2014;147:1712-4.

6. Kato H, Gandhi SK. Use of Berlin Heart ventricular assist devices as a total artificial heart. J Thorac Cardiovasc Surg. 2018;156:743-5.

7. VanderPluym CJ, Khoo NS, Rebeyka IM, Buchholz H. Unique case of total artificial cardiac support in failed Fontan circulation after cardiectomy: is continuous flow better than pulsatile flow? J Thorac Cardiovasc Surg. 2013;145:e62-3. 